International Journal of Instruction e-ISSN: 1308-1470 • www.e-iji.net

Article submission code: 20201213233603

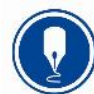

October $2021 \bullet$ Vol.14, No.4

p-ISSN: 1694-609X

pp. $825-840$

Received: 13/12/2020

Revision: 28/04/2021
Accepted: 23/05/2021

OnlineFirst: 02/09/2021

\title{
Achievement Emotions and Gender Differences Associated with Second Language Testing
}

\section{Peter Reilly}

Prof., Universidad Panamericana, Aguascalientes, México, preilly@up.edu.mx

\section{Javier Sánchez-Rosas}

Researcher, Universidad Nacional de Córdoba, Argentina, jsanchezrosas@unc.edu.ar

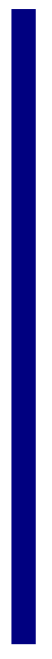

\begin{abstract}
The results of second language (L2) tests influence important life events such as university graduation, access to scholarships, and employment opportunities. Curiously, few studies have examined L2 exam-related emotions beyond anxiety. Emotions are important because they influence mediators such as motivation, the use of executive functions, and higher-level learning strategies, which in turn, influence test performance. This study identified the positive and negative achievement emotions experienced by 277 L2 university learners in Mexico. Findings based on independent t-tests revealed that, contrary to previous research suggesting that test anxiety dominates the testing experience, learners experience positive emotions (e.g., hope) more frequently than negative ones (e.g., shame). Furthermore, upon comparing the global averages of four positive emotions and four negative emotions, a robust difference was found $(\mathrm{d}>.80)$ favouring the positive emotions. Comparisons between genders showed that exam-related emotions favour males. It was concluded that $\mathrm{L} 2$ researchers ought to broaden the research agenda regarding exam-related emotions beyond test anxiety. Further, educators ought to implement teaching strategies that promote a positive emotional experience surrounding L2 testing, thereby improving test performance.
\end{abstract}

Keywords: second language testing, achievement emotions, test anxiety, adult language learner, control-value theory

\section{INTRODUCTION}

The results of English language (EL) tests influence a person's life in significant ways: access to scholarships, employment opportunities, university graduation, and salary. For example, the Mexican government sponsors students who wish to study a postgraduate degree abroad only if they earn a 550 on the TOEFL. Regarding jobs, international companies require candidates to pass EL exams and take interviews with native speakers before they are hired for certain positions. Regarding graduation, universities in Mexico require students pass a certain number of levels of English and/or pass standardized exams to certify their English level.

Citation: Reilly, P., \& Sánchez-Rosas, J. S. (2021). Achievement emotions and gender differences associated with second language testing. International Journal of Instruction, 14(4), 825-840. https://doi.org/10.29333/iji.2021.14447a 
Not surprisingly, a variety of emotions surround the EL testing experience. Emotions pervade all human activity (Keltner et al., 2019) and influence factors that underpin learning. For example, researchers have found that positive emotions improve student attention, self-regulated learning, level of boredom, and the tendency for life-long learning (e.g., Diamond, 2013; Oates, 2019). Because emotions are woven into so many aspects of learning, they warrant researchers' attention. They also emerge within and influence us differently (Pekrun, 2014). For example, high achievers experience more enjoyment and hope when learning; while low achievers report more anxiety and hopelessness (Reilly \& Sánchez Rosas, 2019). Understanding the nuances that exist among different types of learners can inform educators how to promote a positive emotional experience by all L2 learners. Importantly, the positive psychology movement (e.g., Seligman, 2011) has motivated educational scientists, including L2 researchers (e.g., MacIntyre \& Gregersen, 2012) to evolve from the focus on the debilitating role of anxiety to the beneficial role of positive emotions such as enjoyment (Dewaele \& MacIntryre, 2016) in the L2 learning process. This study intends to build on this previous work by focusing on exam-related emotions and possible differences between genders.

Exam-related emotions (Pekrun, 2014) have been explored, but identifying which ones emerge in the L2 context is still pending. Further, gender differences regarding examrelated emotions have not been explored. Therefore, this study identified two objectives to fill these gaps: first, to explore the exam-related emotions of university students who study English as a foreign language; and second, to examine if any differences exist between genders. These two objectives are valuable because emotions influence learning and performance (Shao et al., 2019). Further, if L2 educators are sensitized to the emotions that emerge, they could adopt strategies to ameliorate the effects of negative emotions and promote positive among their students. The theoretical framework used in this study is control-value theory (Pekrun, 2014) and the achievement emotions (AEs) (i.e., emotions that arise in educational settings) associated with it.

\section{Literature Review}

\section{Defining emotions and their importance}

Defining emotions is challenging. In fact, Izard (2010) surveyed 34 scientists and found "no consensus on a definition of emotion" (p. 363). However, it is generally accepted that an emotion is a combination of perceptions, brain activity, labeling of feelings, and behavioral reactions. One researcher, Scherer (2005), discussed five components of an emotion, which are presented here in the context of L2 testing. If a language teacher announces the date of the final exam, a student first makes a cognitive appraisal about it (e.g., She thinks "Oh no!" because of past test experiences). Second, a bodily reaction emerges (e.g., butterflies in the stomach and the amygdala activates to manage the fearful situation). Third, facial and vocal expressions appear (e.g., downward movement of the corners of the mouth and a grunt). Fourth, a feeling component materializes (e.g., She labels the situation as anxiety-provoking). Finally, the behavioral component is 
activated (e.g., She organizes her notes and begins studying). Keltner et al. (2019) added that emotions enable people to adapt to environmental changes, thereby improving the quality of their life. In the case of an L2 student facing an exam, one can imagine how helpful the ability to lessen one's anxiety and increase hope would be.

\section{Expanding research beyond test anxiety}

To date, language anxiety, or the negative emotional reaction that emerges when learning or using a L2 (Zheng \& Cheng, 2018), and test anxiety, or the worry and fear of failure that occur during test situations (Wang \& Zhan, 2020), have received the bulk of the attention in SLA research on affect. Although anxiety has been associated with lower achievement, it can also provoke language learners to develop resilience (Méndez López, 2011).

Qualitative studies have revealed that L2 learners experience emotions far beyond anxiety (e.g., Méndez López, 2011, fear and frustration; Oxford, 2015a, interest and happiness). These researchers used qualitative designs to analyse learners' journals (Méndez López, 2011) and personal narratives (Oxford, 2015b). However, they did not examine exam-related emotions, per se. The current study will differ from these investigations in two ways. First, it will shed a direct light on exam-related emotions. Second, it is quantitative in nature by using an instrument designed to measure eight exam-related emotions based on Pekrun et al.'s (2007) control-value theory and AEs framework.

Over the past decade, the burgeoning of positive psychology (e.g., MacIntyre et al., 2016; Seligman, 2011) has contributed to the view that positive emotions supersede anxiety in importance in the L2 classroom. Dewaele \& MacIntyre's studies (2016) revealed that L2 learners report more enjoyment than anxiety when learning, and L2 instructors ought to boost learners' positive affect, rather than be too concerned about anxiety. Considering that educational researcher (e.g., Goetz et al., 2007) have shown that positive emotions enhance learning and performance, it seems wise that SLA studies continue to explore the nature and benefits of positive emotions.

\section{Exam-related emotions of EFL learners in Mexico}

Researchers (e.g., Méndez López \& Bautista Tun, 2017) have examined the emotional experience of Mexican EFL learners. Again, their studies did not focus on exam-related emotions directly; however, they shed light on those surrounding learning. Méndez López's (2011) analysed the journals of 24 university students, finding that fear, happiness, worry, calm, sadness, and excitement were most common. Exam-related emotions that emerged included worry about whether they would pass; frustration with the inability to speak fluently during an oral test; sadness due to becoming distracted during exams; and being upset when grades were lower than expected.

In a second study in Mexico, Méndez López and Bautista Tun (2017) analysed journals and interviews of university EFL learners. They found males reported a wider range of negative emotions, while females experienced negative emotions more frequently. 
Regarding exam-related emotions, both genders reported feeling text-anxiety; shame during an oral exam; and frustration due to poor exam performance.

Reilly and Sánchez Rosas (2019) completed a third study in Mexico regarding L2 learning-related emotions. They confirmed previous findings that males and highachievers report a more favourable emotional experience. The current study will extend this work in Mexico on learning-related emotions by identifying the exam-related emotions of L2 learners through the lens of Pekrun et al.'s (2007) control-value theory.

\section{Control-value theory}

L2 researchers and educators need to look beyond our field and learn from investigations by educational psychologists (Shao et al., 2019). Control-value theory (Pekrun, et al. 2007) posits that AEs are those emotions that arise in educational settings and are tied to learning activities or outcomes. Learners' emotions are determined by their cognitive appraisal of control and value of activities and outcomes. For example, a language learner may experience positive emotions (e.g., enjoyment) if exams are perceived as controllable (e.g., the student believes he can achieve a high score) and of value (e.g., the student views the exam result as helpful). Conversely, the learner may experience negative emotions (e.g., hopelessness) if a positive result is viewed as unattainable (e.g., exam topics cannot be mastered) or if the exam is unimportant (e.g., the test has no intrinsic or extrinsic value). AEs can also be categorized as prospective outcome emotions if they imply a future orientation (e.g., hope, anxiety about an upcoming exam) or retrospective outcome emotions if they imply a past orientation (e.g., pride, shame after receiving exam results) (Shao et al., 2019).

Achievement emotions are important for numerous reasons. First, Diener (2000) stated that emotions influence one's overall sense of well-being, and encourage one to adopt a path of life-long learning. Also, they enhance learning because they activate factors that underpin learning including attention control (Diamond, 2013); self-regulated learning (Oates, 2019); motivation to learn (Løvoll el al., 2017); use of higher-level learning strategies (Pekrun, 2014); and grit (Li et al., 2019). These mediators underpin learning and improve test performance (Shao et al., 2019).

\section{Eight exam-related AEs}

The present perspective is that the research agenda on exam-related emotions should extend beyond test anxiety. L2 educators ought to benefit from the progress of educational researchers (e.g., Shao el al., 2019) who have identified four positive AEs (enjoyment, hope, pride, and relief) and four negative AEs (anger, anxiety, shame, and hopelessness) associated with testing (Table 1). For example, pride emerges when a learner obtains a positive outcome that he attributes to his own effort or ability (e.g., earning a high exam score after careful preparation). Hopelessness, on the other hand, emerges when a positive outcome is viewed as unattainable (e.g., a learner anticipates that an exam will be too difficult to pass). Considering that $\mathrm{L} 1$ learners have reported a variety of AEs when testing (Pekrun et al., 2007), this study hypothesizes that L2 
learners will report them as well. Importantly, while the table might suggest that these emotions arise independently on one another, the opposite is likely true. For example, not surprisingly, an L2 learner who has not achieved a required score on the TOEFL previously, may experience a combination of shame, anxiety, and hopelessness as the next exam approaches.

Table 1

Eight exam-related AEs (Pekrun et al., 2007)

\begin{tabular}{ll}
\hline Emotion & Instigated by a(n): \\
\hline Enjoyment $(+$, act. $)$ & outcome that is perceived as controllable and valuable \\
\hline Hope $(+$, act. $)$ & outcome that is perceived as controllable and success is anticipated \\
\hline Pride $(+$, act.) & successful outcome that is attributed to oneself \\
\hline Relief $(+$, deact.) & non-occurrence of expected outcome failure \\
\hline Anger (-, act.) & outcome failure that is attributed to others \\
\hline Anxiety (-, act.) & outcome that is controllable but failure is anticipated \\
\hline Shame (-, act.) & outcome failure that is attributed to oneself \\
\hline Hopelessness (-, deact.) & successful outcome that is perceived as not being attainable \\
\hline
\end{tabular}

Note: + refers to a positive emotion; - refers to a negative emotion; act. refers to an activating emotion, i.e., one that promotes action. deact. refers to a deactivating emotion, i.e., promotes inaction by the learner.

\section{AEQ and gender differences when L2 learning}

To date, three studies involving L2 learners have utilized the Achievement Emotions Questionnaire (AEQ), based on Pekrun et al.'s (2007) control-value theory. These studies focused on learning-related emotions, not those associated with testing. Tan (2017) found that Chinese university students reported more positive than negative AEs. Yükselir and Harputlu (2014) used the AEQ with Turkish university EFL learners and discovered that males reported more pride and enjoyment, and females more anxiety and shame. In a third study, Reilly and Sánchez Rosas (2019) also found that male EFL learners reported experiencing pleasant learning-related emotions more frequently than their female counterparts. The current study extends this investigation to exam-related emotions.

Importantly, research that did not use the AEQ suggests that females are not at an emotional disadvantage in the L2 classroom. Rather, they are more emotionally involved in the process. In two studies (Dewaele \& MacIntyre, 2016; Dewaele et al., 2018), females reported more positive emotions such as pride and, simultaneously, more negative emotions such as anxiety than males. Again, these studies did focus on examrelated emotions, a fact which lends importance to the current study. These findings may have revealed contradictory results because of cultural and teaching differences and/or the distinct instruments used to measure emotions.

Because AEs influence learning and performance (Sánchez Rosas \& Esquivel, 2016), it is valuable to continue the exploration of gender differences when L2 testing. A better understanding may help L2 educators make informed decisions about the teaching strategies they use, especially to aid females. 


\section{The present study}

Although L2 research on emotions that arise when learning has expanded, those that surround testing remain unexplored. Therefore, the first research question is: What AEs do L2 learners experience when testing? Pekrun et al.'s (2007) AEQ will measure which exam-related emotions emerge. The second question is: Do different AEs emerge between genders when L2 testing?

If educators had answers to these questions, they could seek to use strategies that would promote the experience of pleasant emotions, which could activate those factors that underpin learning and test performance. Regarding RQ1, due to prior research (Horwitz, 2010), there is a temptation to hypothesize that anxiety will be most associated with L2 testing. However, because recent studies (e.g., Dewaele et al., 2018) have revealed that L2 learning is more pleasant than unpleasant, it is hypothesized that subjects will report experiencing a variety of emotions beyond test anxiety. Further, they may report more pleasant that unpleasant emotions. Regarding RQ2, it is hypothesized, based on prior research in Mexico (Reilly \& Sánchez, 2019), that males will report experiencing positive emotions more frequently than females surrounding testing. Dewaele et al.'s (2018) finding would suggest differently (i.e., because females are more emotionally involved, they will report higher levels of both positive and negative emotions). However, because prior research on learning-related emotions in Mexico favoured males (Méndez López \& Bautista Tun, 2017; Reilly \& Sánchez Rosas, 2019), it was hypothesized that a similar finding would emerge regarding exam-related emotions. A final clarification: this study will not seek causal relationships between emotions, gender, and performance, rather reveal which AEs are more commonly associated with L2 testing.

\section{METHOD}

\section{Participants}

Participants in this study included 277 EFL learners from one private $(\mathrm{n}=103)$ and one public $(\mathrm{n}=174)$ university in Central Mexico. They included 161 women $(58.1 \%)$ and 116 men $(41.9 \%)$, with a mean age of 19.7 years $(\mathrm{SD}=1.34)$. Women outnumbered men due to the enrolment tendency in English language courses during the semester the study took place. The majority of students were Mexican ( $\mathrm{n}=264 ; 95.3 \%)$, whereas 13 (4.7\%) participants self-reported being international students. It was decided to include the international students in the study because of their similar profile (e.g., age, status as university students, spoke Spanish as their L1). The reported academic level of the participants reflected students in their freshman $(n=217 ; 78.3 \%)$, sophomore $(n=48$; $17.3 \%)$, junior $(\mathrm{n}=10 ; 3.6 \%)$, and senior $(\mathrm{n}=2 ; 0.7 \%)$ years. Participants were distributed among basic $(n=62 ; 22.3 \%)$, intermediate $(n=82 ; 29.6 \%)$, and advanced ( $n$ $=133 ; 48.1 \%)$ English levels of the program. Participants were enrolled in one of four different schools within the universities: business (35\%); engineering (30\%); education (20\%); and law (15\%). Students reported studying English five hours per week for a total of 80 hours per semester. A standard communicative, four-skill textbook was used 
in each of the seven levels of the programs. During each 16-week course, students took a formative achievement exam in the $6^{\text {th }}$ and $12^{\text {th }}$ week and a final, summative achievement exam at the end of the course. A score of 550 on the paper-based TOEFL, which corresponds to a $\mathrm{C} 1$ level on the $\mathrm{CEF}$, was a graduation requirement for students at the private university; a B1 level was a graduation requirement for the students at the public university. Spanish was the L1 of all but three students.

\section{Instrument}

To collect data, an online, Spanish version of the AEQ, namely the AEQ-Argentine (AEQ-AR), was applied to the participants. This instrument demonstrated high validity and reliability during administrations in Argentina (Sánchez Rosas, 2015). The purpose of the instrument is to collect data on eight emotions that learners may experience when taking exams. Specifically, the AEQ-AR reports on the experience of four positive emotions. Sample items from the instrument are presented in italics. The positive emotions include enjoyment: For me, the test is a challenge that is enjoyable; hope: I have great hope that my abilities will be sufficient; pride: I am proud of how well I mastered the exam, and relief: I feel very relieved. The AEQ-AR also reports on the experience of four negative emotions, including anger: I am fairly annoyed; anxiety: I feel panicky when writing an exam; shame: I feel ashamed; and hopelessness: I have lost all hope that I have the ability to do well on the exam. The instrument uses a 5point Likert scale, including 1) never; 2) rarely; 3) sometimes; 4) often; and 5) always. There are 5 to 7 items pertaining to each emotion. Sanchez Rosas (2015) found high internal consistency among items for the eight emotions with Cronbach alpha calculations ranging from .82 to .92 .

\section{Procedure}

Participants were introduced to the online questionnaire by their course teacher at the beginning of the Fall 2019 semester. The primary researcher asked 10 EFL professors to explain to students that, although participation was voluntary, the results would help the language department understand students' test-taking experience. Then, strategies could be designed to help students improve their test-taking ability. During the sixth, seventh, and eighth weeks of the semester, the questionnaire was made available online via the course website. Importantly, the questionnaire specifically instructed students to only consider their experience when taking English language exams. Also, the instrument was applied outside of exam week. These steps were taken so that, as much as possible, students could focus on L2 exam-related emotions, and not those associated with other subjects.

Ten groups from the private university and five groups from the public university participated in the study. At the private university, 122 of 150 students $(81.3 \%)$ completed the survey. At the public university, 166 of 180 students $(92.2 \%)$ completed the instrument. Finally, consent forms were distributed to and collected from all participants. The form contained information about the purpose, procedures, and 
benefits of the study; an explanation of how to access the results of the research; and the researchers' contact information.

\section{FINDINGS}

\section{Positive vs. negative exam-related AEs}

To answer the primary research objective, descriptive statistics were gathered on the eight exam-related emotions (Table 2), including the means, standard deviation, skewness, and kurtosis for each of them. The assumption of normally distributed scores was examined and satisfied based on the fact that the skew and kurtosis levels were estimated to be less than the maximum allowable values for a t-test (i.e., skew < $|2.0|$ and kurtosis $<|9.0|$; Posten, 1984). Then, the averages of the four positive and four negative emotions were calculated and compared using a paired samples t-test. Results revealed that the mean of the positive exam-related emotions $(\mathrm{M}=3.45, \mathrm{SD}=$ 0.72 ) was significantly higher than the mean of the negative emotions $(\mathrm{M}=2.11, \mathrm{SD}=$ $0.83, \mathrm{p}<.001, \mathrm{~d}=1.71)$. Cohen's $\mathrm{d}$ indicates a large effect size for the difference between positive and negative emotions (Cohen, 1992). Thus, learners reported experiencing positive exam-related AEs more frequently than the negative ones. Cronbach alpha calculations for the eight emotions revealed high internal consistency, ranging from .88 to .95 .

Table 2

Descriptive statistics of eight exam-related emotions and the results of paired t-test comparing the means of the positive and negative emotions

\begin{tabular}{|c|c|c|c|c|c|c|}
\hline & \multicolumn{4}{|c|}{ Descriptive statistics } & & \\
\hline Emotion & M & SD & Skew & Kurtosis & & \\
\hline Enjoyment & 3.22 & 0.84 & -0.04 & -0.15 & & \\
\hline Hope & 3.59 & 0.81 & -0.42 & -0.03 & & \\
\hline Relief & 3.53 & 0.97 & -0.19 & -0.15 & & \\
\hline Pride & 3.44 & 0.82 & -0.34 & -0.17 & & \\
\hline Anger & 1.81 & 0.84 & 1.21 & 1.11 & & \\
\hline Anxiety & 2.67 & 0.93 & 0.27 & -0.42 & & \\
\hline Shame & 2.03 & 0.99 & 0.90 & 0.04 & & \\
\hline Hopeless & 1.91 & 0.98 & 1.16 & 0.75 & & \\
\hline Positive emo & 3.45 & 0.72 & -0.29 & 0.19 & Paired t-test resul & \\
\hline Negative emo & 2.11 & 0.83 & 0.88 & 0.33 & $\mathrm{t} \quad \mathrm{df}$ & $\mathrm{d}$ \\
\hline \multicolumn{5}{|c|}{ Positive vs negative emotions } & $18.19 * * * \quad 276$ & 1.71 \\
\hline
\end{tabular}

Note: All items were rated on a 5-point Likert-type scale

$* * * \mathrm{p}<=.001, \mathrm{n}=277$ 


\section{Achievement emotions and gender}

As shown in Table 3, results revealed that males reported experiencing all four positive emotions - enjoyment, hope, pride $(\mathrm{p}<.01)$, and relief $(\mathrm{p}<.05)$ - more frequently than females. In addition, males reported experiencing one negative emotion (anger) more than females $(p<.05)$. Differences for the other three negative emotions (anxiety, shame, and hopelessness) were nonsignificant. The average of positive emotions was significantly higher for males $(\mathrm{M}=3.62, \mathrm{SD}=0.64)$ than for females $(\mathrm{M}=3.32, \mathrm{SD}=$ $0.76)$ at the $p<.01$ level. Cohen's $d$ indicates a low effect size. The average of the negative emotions between genders was nonsignificant.

Table 3

Means, standard deviations, and t-tests results of students' reports of the AEs by gender

\begin{tabular}{|c|c|c|c|c|c|c|c|}
\hline & \multicolumn{4}{|c|}{ Descriptive Statistics } & \multicolumn{3}{|c|}{ Independent t-test } \\
\hline Emotion & Fema & & Males & & & & \\
\hline & $\mathrm{M}$ & SD & $\mathrm{M}$ & SD & $\mathrm{T}$ & Df & $\mathrm{d}$ \\
\hline Enjoyment & 3.08 & 0.86 & 3.41 & 0.77 & $-3.32 * *$ & 275 & 0.40 \\
\hline Hope & 3.47 & 0.86 & 3.77 & 0.70 & $-3.11 * *$ & 275 & 0.38 \\
\hline Pride & 3.33 & 0.85 & 3.60 & 0.76 & $-2.71 * *$ & 275 & 0.33 \\
\hline Relief & 3.41 & 1.02 & 3.68 & 0.86 & $-2.34 *$ & 275 & 0.28 \\
\hline Anger & 1.68 & 0.71 & 1.99 & 0.97 & $-3.05 * *$ & 275 & 0.36 \\
\hline Anxiety & 2.72 & 0.94 & 2.61 & 0.93 & 0.96 & 275 & 0.11 \\
\hline Shame & 2.06 & 0.98 & 1.99 & 1.01 & 0.59 & 275 & 0.07 \\
\hline Hopeless & 1.92 & 0.96 & 1.89 & 1.00 & 0.25 & 275 & 0.03 \\
\hline Positive & 3.32 & 0.76 & 3.62 & 0.64 & $-3.39 * *$ & 275 & 0.41 \\
\hline Negative & 2.10 & 0.79 & 2.12 & 0.88 & -0.23 & 275 & 0.02 \\
\hline
\end{tabular}

Note: All items were rated on a 5-point Likert-type scale

$* \mathrm{p}<=.05 ; * * \mathrm{p}<=.01$

${ }^{\mathrm{a}} \mathrm{n}=161 ;{ }^{\mathrm{b}} \mathrm{n}=116$

\section{DISCUSSION}

L2 test results influence people's lives; therefore, emotions pervade the testing experience. As such, this study sought to determine the AEs that surround L2 testing, and whether they vary between genders. Although prior research (Horwitz, 2010) emphasized the role of L2 test anxiety, we hypothesized that more positive emotions would arise. In fact, our results revealed that both discrete and global emotions indicate a favourable emotional experience by subjects. Moreover, the difference between global positive and negative emotions was found to be large $(d>0.80$, Cohen, 1992).

According to control-value theory (Pekrun et al., 2007), AEs depend on appraisals of value and control. Therefore, these results suggest that students valued outcomes and/or had control over them. Another notable finding is that enjoyment was reported less frequently than hope, pride, and relief. This is important because, after anxiety dominated the research on affective variables for decades (Horwitz, 2010), enjoyment emerged as predominant (e.g., Dewaele \& MacIntyre, 2016). This study finds that other 
AEs warrant similar attention, especially as they relate to testing. It is likely that these other AEs emerge because exams influence life events (e.g., graduation, job offers), and thereby activate prospective outcome emotions (e.g., hope) and retrospective outcome emotions (e.g., pride, relief).

This study also examined possible gender differences. As expected, males reported more positive exam-related emotions, aligning with prior research on learning-related emotions in L2 (Reilly \& Sánchez Rosas, 2019; Sánchez Rosas, 2015), and L1 research when testing. This suggests that males view exams as an enjoyable challenge, have more confidence in their abilities, feel proud of their knowledge, and do not suffer the anxiety that females might. The finding that males reported more anger may be explained by contextual factors such as time pressures, correction criteria, or the amount of material being evaluated. To clarify, although males reported anger, it was less frequent than positive emotions. The upshot of gender results favoured males, although these differences revealed small effect sizes.

Interestingly, regarding females, although prior research in Argentina (Sánchez Rosas, 2015), Turkey (Yükselir \& Harputlu, 2014), and China (Tan, 2017) revealed that they experienced negative AEs more frequently, this study of Mexican females did not. One plausible explanation is that, in this study, positive AEs were higher across the board. As positive AEs increase, negative ones logically decrease. A second possibility is that the gender ratio in this study favoured females (58 to $41 \%$ ). This may have influenced the learning environment in favour of females, perhaps by decreasing competitiveness or increasing cooperativeness, which in turn attenuated their reports of negative AEs.

\section{IMPLICATIONS}

Two theoretical implications can be taken from these results. First, researchers ought to benefit from gains by psychological researchers in the area of achievement emotions (Shao et al., 2019) and the positive psychology (Seligman, 2011) to expand the research agenda surrounding testing beyond anxiety.

Second, the challenge arises about why males report more pleasant emotions than females. To date, L2 researchers have yet to shed light on this issue. Curiously, Balart and Oosterveen (2019) expressed that, on average, females perform better on L1 verbal ability exams. They reported that females prepare better for tests, plan more carefully how to take them, and show more sustained effort when taking tests. Although these findings would suggest that the experience of L2 testing would favour females, the findings herein are to the contrary (i.e., males reported more positive emotions). Perhaps the answer to this question lies in the nature of the AEQ, which is based on test-takers' appraisals of control and value. According to Balart and Oosterveen (2019), males express more self-confidence when taking exams. Hence, this could lead them to report higher levels of control, and hence enjoyment, hope, and pride.

Regarding classroom implications, teachers need to cultivate pleasant emotions around test-taking (Pekrun, 2014). Shao et al. (2019) stated that researchers have yet to identify 
"practical recommendations for language teachers" in light of AE research (p. 8). To respond, this section will identify strategies that teachers could implement prior to, during, and after testing to promote the experience of positive emotions surrounding L2 testing.

\section{Prior to exams}

L2 teachers need to regularly identify the learning objectives which will enable learners to view L2 learning and exam success as achievable (Pekrun, 2014; Sides \& Cuevas, 2020). If learners see objectives are linked to academic and professional goals, they will make a value appraisal, which will increase enjoyment and reduce boredom (Sánchez Rosas, 2019). Second, if students are given the chance to complete simulations of exam sections, they become familiar with the knowledge and skills necessary for success (Almarode \& Vandas, 2018), thereby breeding confidence and hope. Teachers should also explain the nature of a growth mindset (Dweck, 2016) and grit (Duckworth, 2016), so learners believe that learning and exam performance depend primarily on effort, i.e., a control appraisal. This may lead to hope and enjoyment when testing, and perhaps pride if success is achieved (Pekrun, 2014).

\section{During testing}

Students are more likely to experience enjoyment and hope if they perceive that exams are based on content and skills practiced in the course. Contrarily, hopelessness and anger will emerge. Further, when students believe that the exam is neither too hard nor too easy, they may enjoy taking the exam; hence, frustration and boredom are less likely. Finally, to reduce mind-wandering (Mrazek et al., 2013) and increase attention control (Diamond, 2013), it is imperative that noise, temperature, and other distractions do not impede concentration. Under these conditions, students are more likely to experience positive emotions and even flow (Oppland, 2020).

\section{After the exams}

According to Pekrun (2014), feedback "is one of the most powerful factors in the development of achievement emotions" (p. 24). Specific, timely feedback (Opitz et al., 2011) that stresses effort above grades (Duckworth, 2016) is the path to success. Hattie and Timperley (2007) explained that specific feedback indicates exactly how learners can improve, which instils a sense of hope about success on future exams. Diamond (2013) added that specificity activates students' executive functions, enabling them to repress distracting thoughts, contemplate strategies to improve, and self-reflect on learning and testing. Simply put, executive functions help students feel more in control about how to perform better, firing the flames of hope. Thinking about how to improve is a form of self-regulated learning (SRL) (Oates, 2019), whereby students create, monitor, and evaluate their own learning. According to Villavicencio and Barnard (2012), such SRL and academic achievement have been associated with pride and hope. Further, when teachers define talent as persistent effort (not ability) (Dweck, 2016), and add that grit (passion and perseverance) (Duckworth, 2016), then students are likely to 
sustain their effort and improve performance. Hence, pleasant emotions such as enjoyment and hope can emerge, and pride may arise as achievement improves.

\section{CONCLUSIONS}

As hypothesized, the results showed that when L2 learners take tests they report numerous emotions beyond anxiety, including both positive and negative ones. Also, reports of both discrete and global positive exam-related emotions were greater than negative ones. This finding is significant not only because it contradicts the traditional focus of test anxiety surrounding testing, but also it serves as a message to L2 researchers to expand their agenda to include positive exam-related emotions such as hope and pride. Such an endeavour could benefit from insights from educational psychology, (e.g., control-value theory and AEs). Further, the finding that females experienced significantly fewer positive emotions when testing confirms prior research in other developing countries (e.g., China, Turkey) but contradicts work in England (Dewaele et al., 2018). These differences may have been caused by cultural differences and/or instruments used to measure emotions. Finally, it is concluded that, in light of this gender difference, L2 educators ought to adopt strategies designed to promote the emergence of positive exam-related emotions among females.

\section{LIMITATIONS}

This study was limited in several ways. The fact that the only robust result with a large effect size that was found was the difference between global positive and negative emotions suggests that the findings should be taken with caution. The effect size related to gender was low. Subsequent studies should explore other contextual and individual variables that may be moderating these differences and inform relationships, such as the type of evaluation or valuations of control and value appraisals that learners assign to tests. In addition, future studies should be designed to determine, for example, whether males value tests more than females, and therefore report greater enjoyment, pride, and hope.

Second, this study involved only Mexican EFL learners. Future research should survey a broader variety of students of different ages, countries, and majors. For example, in Mexico, as in other Latin American countries, females are three times more likely to be neither in school nor employed. Considering that emotions motivate behaviour and are linked to successful learning, it is imperative that researchers identify how emotions influence cognitive, motivational, and behavioural processes when testing, especially as they pertain to females.

Finally, this study focused on the emotions surrounding course exams, rather than those related to standardized instruments such as the TOEFL and Cambridge exams. Researchers might find that emotions vary when stakes are higher, for example, when passing the TOEFL is a graduation requirement. 


\section{REFERENCES}

Almarode, J. \& Vandas, K. (2018). Clarity for learning. Sage/Corwin: Thousand Oaks, California.

Balart, P., \& Oosterveen, M. (2019). Females show more sustained performance during test-taking than males. Nature communications, 10(1), 3798. https://doi.org/10.1038/s41467-019-11691-y

Cohen, J. (1992). A power primer. Psychological Bulletin, 112, 155-159.

Dewaele, J-M., \& MacIntyre, P. (2016). Foreign language enjoyment and foreign language classroom anxiety. The right and left feet of FL learning? In: MacIntyre, P. and Gregersen, T. and Mercer, S. (eds.) Positive Psychology in SLA. Bristol, UK: Multilingual Matters, pp. 215-236. ISBN 9781783095353.

Dewaele, J.M., Witney, J., Saito, K.; \& Dewaele, L. (2018) Foreign language enjoyment and anxiety: The effect of teacher and learner variables. Language Teaching Research, $22(6), 676-697$.

Diamond A. (2013). Executive functions. Annual review of psychology, 64, 135-168. https://doi.org/10.1146/annurev-psych-113011-143750

Diener, E. (2000). Subjective Well-Being: The science of happiness and a proposal for a national index. The American psychologist, 55, 34-43. 10.1037/0003-066X.55.1.34.

Duckworth, A. (2016). Grit: The power of passion and perseverance. Scribner/Simon \& Schuster.

Dweck, C., (2016). Mindset: The New Psychology of Success. 2nd ed. New York: Random House.

Goetz, T, Preckel, F., Pekrun, R., \& Hall, N. (2007). Emotional experiences during test taking: Does cognitive ability make a difference? Learning and Individual Differences, 17(1), 3-16.

Hattie, J. \& Timperley, H. (2007). The power of feedback. Review of Educational Research, 77(1), 81-112 doi: 10.3102/003465430298487

Horwitz, E. (2010). Foreign and second language anxiety. Language Teaching, 43(2), 154-167. doi:10.1017/S026144480999036X

Izard, C. E. (2010). The many meanings/aspects of emotion: Definitions, functions, activation, and regulation. Emotion Review, 2(4), 363-370.

Keltner, D., Sauter, D., Tracy, J., \& Cowen, A. (2019). Emotional expression: Advances in basic emotion theory. Journal of nonverbal behaviour, 43(2), 133-160. https://doi.org/10.1007/s10919-019-00293-3 
Li, J., Lin, L., Zhao, Y., Chen, J., \& Wang, S. (2018). Grittier Chinese adolescents are happier: The mediating role of mindfulness. Personality and Individual Differences, $131,232-237$.

Løvoll, H. S., Røysamb, E., \& Vitters $\varnothing$, J. (2017). Experiences matter: Positive emotions facilitate intrinsic motivation. Cogent Psychology, 4(1), doi: $10.1080 / 23311908.2017 .1340083$

MacIntyre, P. D., \& Gregersen, T. (2012). Emotions that facilitate language learning: The positive-broadening power of the imagination. Studies in Second Language Learning and Teaching, 2(2), 193-213.

Méndez López, M. G. (2011). The motivational properties of emotions in Foreign Language Learning. Columbian Journal of Applied Linguistics, 13(2), 43-59.

Méndez López, M. G., \& Bautista Tun, M. (2017). Motivating and demotivating factors for students with low emotional intelligence to participate in speaking activities. Profile Issues in Teachers' Professional Development, 19(2), 151-163. http://dx.doi.org/10.15446/profile.v19n2.60652.

Mrazek, M. D., Franklin, M. S., Phillips, D. T., Baird, B., \& Schooler, J. W. (2013). Mindfulness training improves working memory capacity and GRE performance while reducing mind wandering. Psychological science, 24(5), 776-781. https://doi.org/10.1177/0956797612459659

Oates, S. (2019) The importance of autonomous, self-regulated learning in primary initial teacher training. Frontiers in Education, 4(102). doi: 10.3389/feduc.2019.00102

Opitz, B., Ferdinand, N. K., \& Mecklinger, A. (2011). Timing matters: the impact of immediate and delayed feedback on artificial language learning. Frontiers in human neuroscience, 5(8). https://doi.org/10.3389/fnhum.2011.00008

Oppland, M. (2020). 8 Ways to create flow according to Mihaly Csikszentmihalyi. Retrieved from https://positivepsychology.com/mihaly-csikszentmihalyi-father-of-flow/

Oxford, R. (2015a). How language learners can improve their emotional functioning: Important psychological and psychospiritual theories. Applied Language Learning, 25(1\&2), 1-15.

Oxford, R. (2015b). Emotion as the amplifier and the primary motive: Some theories of emotion with relevance to language learning. Studies in Second Language Learning and Teaching, 5(3), 371-393.

Pekrun, R. (2014). Emotions and learning. UNESCO Educational Practice Series, 24. Retrieved from https://unesdoc.unesco.org/ark:/48223/pf0000227679/PDF/227679eng .pdf. multi 
Pekrun, R., Frenzel, A., Goetz, T., \& Perry, R. P. (2007). The control-value theory of achievement emotions: An integrative approach to emotions in education. In P. A. Schutz \& R. Pekrun (Eds.), Emotions in education (pp. 13-36). San Diego: Academic Press.

Posten, H. O. (1984). Robustness of the two-sample t-test. In D. Rasch and M. L. Tiku (Eds.), Robustness of statistical methods and nonparametric statistics (pp. 92-99). Dordrecht, Germany: Reidel.

Reilly, P. \& Sánchez Rosas, J. (2019). The achievement emotions of English language learners in Mexico, Electronic Journal of English Language Teaching, 16(1), 34-48.

Sánchez Rosas, J. (2015). The Achievement Emotions Questionnaire-Argentine (AEQAR): Internal and external validity, reliability, gender differences and norm-referenced interpretation of test scores. Evaluar, 15, 41-74.

Sánchez Rosas, J. \& Esquivel, S. (2016). Instructional teaching quality, task value, selfefficacy, and boredom: A model of attention in class. Revista de Psicología, 25(2), 1-20. http://dx.doi.org/10.5354/0719-0581.2017.44966

Scherer, K. (2005). What are emotions? And how can they be measured? Social Science Information, 44, 695-792. 10.1177/0539018405058216.

Seligman, M. E. P. (2011). Flourish: A visionary new understanding of happiness and well-being. Free Press.

Shao, K., Pekrun, R., \& Nicholson, L. (2019). Emotions in classroom language learning: What can we learn from achievement emotion research? System, 86. https://doi.org/10.1016/j.system.2019.102121.

Sides, J. D. \& Cuevas, J. A. (2020). Effect of goal setting for motivation, Self-Efficacy, and Performance in Elementary Mathematics. International Journal of Instruction, 13(4), 1-16.

Tan, J. (2017). Relationships between achievement emotions, motivation, and language learning strategies of high, mid and low English language achievers. Journal of Literature and Art Studies, 7(6), 770-778. doi: 10.17265/2159-5836/2017.06.014

Villavicencio, F.T. \& Bernardo, A.B. (2013). Positive academic emotions moderate the relationship between self-regulation and academic achievement. The British Journal of Educational Psychology, 83(2), 329-340. doi: 10.1111/j.2044-8279.2012.02064.x.

Wang, W. \& Zhan, J. (2020). The relationship between English language learner characteristics and online self-regulation: A structural equation modelling approach. Sustainability, 12, 3009. doi:10.3390/su12073009

Yükselir, C., \& Harputlu, L. (2014). An investigation into EFL prep-class students' academic emotions. Journal of Language and Linguistics Studies, 10(2), 100-119. 
Zheng, Y., Cheng, L. (2018). How does anxiety influence language performance? From the perspectives of foreign language classroom anxiety and cognitive test anxiety. Language Testing in Asia, 8(13). Retrieved from https://doi.org/10.1186/s40468-0180065-4 